\title{
KITTLER, FRIEDRICH. MIÍDIAS ÓPTICAS: CURSO EM BERLIM, 1999. TRADUÇÃO DE MARKUS HEDIGER. RIO DE JANEIRO: CONTRAPONTO, 2016. 344 p.
}

\author{
Gabriel Salvi Philipson ${ }^{1}$ \\ Universidade Estadual de Campinas, Campinas, São Paulo, Brasil \\ Freie Universität Berlin, Berlim, Alemanha \\ gsphilipson@gmail.com
}

\section{Il sole non vide mai nessuna ombra}

Catorze vezes, em catorze preleções sobre as mídias ópticas, resisti a todas as tentações de escrever meus próprios programas de computação gráfica (independentemente do que possa significar "meus próprios" em termos de algoritmos). Em vez disso, criei - sob o ditado de um processador de textos chamado WORD 5.0 - simples e entediantes manuscritos para minha aula. [...] Sob os auspícios da alta tecnologia, porém, todo este curso foi uma tremenda perda de tempo (pp.330 $1)$.

Mídias ópticas, o primeiro livro de Friedrich Kittler (1943-2011) em português saiu no Brasil em boa hora, e não apenas para que pudesse ser vendido na $18^{\mathrm{a}}$ Festa do Livro da USP a preço de atacado. Passava do momento de o público brasileiro - não somente o especializado - tomar conhecimento do trabalho ímpar deste teórico das mídias e germanista, e esta primeira tradução de uma obra sua, com apoio do Goethe Institut, deve ser o passo inicial para mudar esse quadro ${ }^{2}$.

A trajetória de Kittler é complexa e notável: tendo estudado língua e literatura alemã e românica, bem como filosofia em Freiburg (onde Heidegger até bem pouco era lei), Kittler que, quando trabalhava na Ruhr-Universität Bochum, convidou Vilém Flusser para que ministrasse aquele que acabaria sendo seu último curso, Comunicologia: reflexões sobre o futuro, de 1991- não apenas é um dos principais introdutores do pensamento francês pósestruturalista na Alemanha. Seus trabalhos - influenciados de Thomas Pynchon, Mcluhan, Turing, acid rock e Leonard Cohen ao menos conhecido Johannes Lohmann, linguista de Freiburg que seria seu precursor (WINTHROP-YOUNG; GANE, 2006, p. 14) - se mostram também como um ponto singular de reencontro de autores como Foucault, Lacan e Derrida com Nietzsche e Heidegger. Talvez fosse mais correto dizer - como ele mesmo o faz: "the import of Foucault and Lacan rests on the fact that their writings allow possible ways of returning to Heidegger without naming him. [...] So my idea was to maintain a critical distance from Heidegger so that I could follow my own path" (ARMITAGE, 2006, p. 20).

\footnotetext{
1 Bolsista Fapesp (2017/27004-7) e DAAD.

${ }^{2}$ Nesse sentido, vale ressaltar aqui o trabalho em andamento de Librandi-Rocha, 2016, no qual começa a pensar Machado de Assis a partir de uma perspectiva kittleriana. Recentemente, foram lançados também $A$ verdade do mundo técnico (2016), pela Editora Contraponto, e Gramofone, filme, typewriter (2019) pelas editoras universitárias da UFMG e da UERJ. No entanto, sua tese de habilitação, Aufschreibesysteme 1800/1900 (1985), ainda não recebeu uma versão em português.
} 
Muitos dos que gostavam de Heidegger usaram desta mesma estratégia, mas o caminho de Kittler é singular provavelmente em relação a todos eles: em Mídias ópticas - talvez o melhor livro introdutório para não iniciados em Kittler, principalmente por sua linguagem mais clara e didática, distante em geral do estilo distintivo e proibitivo que caracteriza sua prosa, seu Kittlerdeutsch ${ }^{3}$ - topamos com uma tentativa, dita de antemão "absurda e provavelmente impossível" (p. 25), de pensar uma história sistematizadora do desenvolvimento conflitante das mídias ópticas desde a pintura sobre a madeira, "com sua perspectiva linear" (p. 16), passando pelas técnicas "já quase antiquadas" (id.) da fotografia, do filme e da televisão, até a computação.

Porém essa história não é pensada como no curso de Hegel sobre as artes, a partir de um pensamento dialético que as sistematiza sob as condições do monopólio do livro - a própria mídia não pensada por meio da qual Hegel pensava. Em primeiro lugar, isso representava o voo da coruja de Minerva do filósofo, afirma ironicamente Kittler: "menos de dez anos após a morte de Hegel, a apresentação pública da fotografia pôs fim ao monopólio de arquivamento dos livros (e, com isso, também dos cursos filosóficos)" (p. 25); e, em segundo, a relação das mídias técnicas conosco é a de um inimigo que toma "a forma da nossa própria questão" (p. 41). Uma relação, portanto, "não da dialética, mas da exclusão ou da inimizade, [que] faz da história da tecnologia algo não tão desumano assim; caso contrário, não diria respeito, absolutamente, às pessoas" (id.). Também não como uma mera história do filme e da televisão, com suas estrelas e celebridades, o que teria se tornado o costume na Alemanha em cursos semelhantes ao que está ministrando, acusa Kittler. Em vez disso, uma história da técnica do filme e da televisão que trata, por um lado, da "relação entre história da técnica e história do corpo" e, "por outro, da relação entre tecnologias modernas e guerras modernas" (p. 38), em uma tentativa de "destacar mais as rupturas e viradas na percepção e nas habilidades artísticas" (p. 60).

Corpo e poder, sexualidade e guerra - os assuntos prediletos de Kittler e que ajudam a explicar sua inclinação por Lacan e Foucault - aparecem em diversos níveis temáticos durante o curso de 1999:

a) da repetição do próprio nome no título do livro que Faulstich organiza ${ }^{4}$ (p. 35), ao propósito dito "ingênuo" do curso: que seus alunos tenham alguma chance em um mercado de trabalho que não exige mais apenas o domínio da antiga arte da escrita, mas também a técnica do processamento digital de imagens (p. 28);

b) da relação entre a fórmula de Euler, a navegação europeia militar e colonialista, e a camera obscura (p. 66), à relação entre os revolvers colts - inventados em 1828 pelo homem branco para dizimar 6 indígenas ou mexicanos por vez, e cujo sistema cilíndrico se volta contra o próprio homem branco na forma de metralhadoras na I Guerra Mundial -, à invenção, por Muybridge, do filme, que usava a mesma forma cilíndrica para fazer, armazenar e reproduzir 24 fotos por segundo, e aos nus fotográficos que o mesmo Muybridge realizou de atletas de Stanford (pp. 218-221);

3 Uma de suas principais características é a investida contra o pronome reflexivo sich que para ele caracterizaria todo o estilo filosófico de Adorno (e dos adornianos) e certo idealismo filosófico do frankfurtiano (e de seus ador(n)adores), ver KITTLER; BANZ, 1996, p. 15). Dos frankfurtianos em geral, aliás, fica dito (para não voltar ao tema) que Kittler não nutria especial simpatia, apesar de todos seus colegas de sua geração terem - em suas próprias palavras - se adornizado. Em Mídias ópticas, alerta-nos logo de início: "não pretendo me perder em lamentos inúteis sobre a arte na era de sua reprodutibilidade técnica" (p. 9).

4 Kritische Stichwörter zur Medienwissenschaft - Stichwörter podendo significar tanto notas (críticas) quanto palavras (críticas) de [Faul]Stich. Kittler tem um olho (se me permitem) acurado para repetições como esta: um célebre momento desta sua capacidade é a sua análise do suspiro ach [ah] com que Fausto - Primeira Parte se inicia, no capítulo inaugural do seu Aufschreibesysteme 1800/1900 (1985). 
c) da (para citar e relacionar de modo fortuito só mais dois exemplos aleatórios e não treinar em demasia a capacidade de respiração do leitor com sentenças intermináveis, as quais tentei amenizar na revisão colocando pontos onde antes havia vírgulas e ponto-e-vírgulas, bem como enumerando de $a$ a $c$ essas relações fortuitas) alma imortal, "isto é, autoarquivadora" (p. 62), que Platão equiparou "a uma tábua de cera, a mídia de sua filosofia" (id.), ao fato de que a fotografia só foi chamada de arte na Europa após seu sucesso criminalístico de controle de delinquentes e de passaporte (p. 202). Kittler chega a esta conclusão após analisar uma citação da comédia de 1865, escrita pelo esquecido jurista e poeta Apollonius von Maltitz, na qual um fotógrafo, após levar ao desespero as hóspedes de um balneário alemão ao representar seus rostos não de modo ideal ou imaginário, como os pintores faziam, mas real, pela fotografia - e, com isso, evidenciar suas feiuras -, restabelece sua honra por ter tirado um retrato de um rapaz que roubava pertences dos hóspedes, o que ajudou a capturá-lo.

Mídias ópticas não são, então, apenas filme, fotografia e televisão, mas devem ser compreendidas de maneira mais ampla (embora não como uma abstração filosófica, e sim como "estruturas do objeto em si” [p. 25]) como um problema sistemático de relações de oposição e combate entre as diversas mídias que ao longo da história realizaram os princípios gerais de arquivar, transmitir e computar imagens. A história delas começa (p. 67), no capítulo “Técnicas visuais", com um louvor ao sol, por revelar aos olhos o que é visível. Passa pela relação entre o zero, o ponto de fuga da perspectiva, a invenção da camera obscura e seu uso pelos pintores para ajudar na "filtragem do sinal" da luz do sol (de Da Vinci a Alberti passando por Brunelleschi, até a invenção da fotografia no século XIX). Prossegue na relação de oposição, combate e aliança entre a perspectiva e a impressão de livros - "a impressão viabilizou o autodidata" (p. 87), pois com ela era possível transmitir o conhecimento de como construir uma camera obscura e o modo como o pintor deveria utilizá-la. Avança no desenvolvimento, em sua relação com técnicas de guerra, do aparelho que fazia o exato oposto da camera obscura: a transmissão das imagens pela laterna magica. E logo chega na apropriação dos jesuítas da laterna magica como um contraponto técnico midiático à técnica da impressão reformista - o contra-ataque das imagens perante o texto se deu com Loyola, o primeiro jesuíta, quem contrapôs à mídia protestante do livro impresso visões psicodélicas ilusórias que motivavam os soldados de Cristo de modo muito mais eficaz, "isto é, inconsciente, do que as obras primas da pintura antiga" (p. 104).

A história das técnicas de mediação entre realidade e representação (na qual se percebe o Foucault heideggerianizado, ou o Heidegger foucaultizado), que não é feita de modo linear, mas por cortes, chega (com alguns saltos) ao iluminismo e ao esclarecimento (palavra com que se costuma traduzir Aufklärung a partir do famoso ensaio de Kant e que, além do mais, poderia ter sido usada para ressaltar o trocadilho de Kittler na página $119^{5}$ ). Avizinha-se, mais especificamente, da relação das novas invenções de Lambert nas mídias ópticas - a fotometria - e o termo que o próprio Lambert cunha em suas reflexões gerais sobre a objetividade das coisas - fenomenologia, "um termo novo que [saindo da matemática] viria a fazer carreira na filosofia" (p. 131): "Em outras palavras (infelizmente pouco usadas pelos filósofos), o idealismo alemão também resultou da história das mídias ópticas" (id.).

$\mathrm{O}$ assunto segue nessa toada, passa por Schiller (um dos Schwerpunkte de Kittler, para o desgosto dos schillerianos) e por como a própria literatura do romantismo alemão teria se

5 "Chegamos então ao século XVIII, que em alemão recebeu o nome de Iluminismo Esclarecimento, e em francês - como que para celebrar as mais recentes invenções ópticas -, o nome muito mais expressivo de Siécle des Lumiéres, Século das Luzes". 
transformado em laterna magica e, portanto, em um tipo de mídia óptica. Mas paro por aqui, pois esta última referência a Hegel leva a uma das principais críticas que se faz a ele: se até a filosofia e o pensamento (da liberdade) em geral é resultado das mídias, o que resta da agência humana? Perante tal questão, respondo com outra: como enfatizar a determinação das mídias sobre "nós" sem que pareça que se transferiu a agência para a técnica? Mas talvez a questão não passe de mera retórica do exagero, segundo as próprias palavras (levianas?) de Kittler, quando confrontado com esta crítica: "I tend to exaggerate in order to get the point across as well as to induce in myself the courage to write a book!" (ARMITAGE, 2006, p. 25).

Muito ainda poderia e deveria ser levantado em uma resenha introdutória de Friedrich Kittler - como o espaço é curto, resta-me apenas fazer o convite: compartilhemos da tarefa de adentrar no incrível mundo das polêmicas (digamos assim) não apenas imanentes à teoria kittleriana? Se sim, que façamos começando pela leitura da elegante tradução ${ }^{6}$ de Markus Hediger de Mídias ópticas, pois ela é capaz de fazer com que nos confrontemos com questões fundamentais do dia-a-dia para as quais normalmente não se costuma dar atenção.

\section{Referências}

ARMITAGE, J. From Discourse Networks to Cultural Mathematics: An Interview with Friedrich A. Kittler". Theory, Culture \& Society. London, vol. 23(7-8), p. 17-38, 2006. Disponível em: http://journals.sagepub.com/doi/pdf/10.1177/0263276406069880 . Acesso em 09 jun. 2017.

KITTLER, F. Aufschreibesysteme 1800/1900. Munique: Fink Verlag, 1985.

KITTLER, F.; BANZ, S. Platz der Luftbrücke: Ein Gespräch. Köln: Oktagon, 1996. Disponível em: https://monoskop.org/images/d/d5/Kittler_Friedrich_Banz_Stefan_1996_Platz_der_Luftbruec ke_Ein_Gespraech.pdf.. Acesso em 09 jun. 2017.

KITTLER, F. Optical Media: Berlin Lectures 1999. Tradução de Anthony Enns. Cambridge, Malden: Polity Press, 2010.

KITTLER, F. Optiche Medien: Berliner Vorlesung 1999. Berlim: Merve Verlag, 2011.

\footnotetext{
${ }^{6}$ A tradução poderia estar mais familiarizada com o modo como alguns termos alemães são traduzidos no Brasil pela tradição filosófica. Para dar só um exemplo - além de Aufklärung, que abordei acima -, allgemein e Allgemeinheit foram traduzidos por geral e generalidade, quando o costume é traduzir, principalmente em contexto hegeliano, por universal e universalidade: “(...) como reconheceu Hegel, a língua pertence ao gerat universal” (p. 198). Embora não prejudique o resultado final do trabalho e comentar tradução seja sempre um trabalho ing rato, é preciso dizer que o defeito mais grave da tradução reside no aposto faltante na página 115 (pode haver outros do tipo): "No final, quando inúmeros diabos, com alcatrão e enxofre, invadem a sala de estudos do erudito para se apoderar do corpo de Cenodoxus, o exercício jesuíta se transforma em certeza teatral e sensual para todos os estudantes presentes[, que representavam a nós, os espectadores atuais]" (meu acréscimo e meu itálico). A versão inglesa, embora menos elegante, não comete a falta: "In the finale, when countless demons stormed out of this gate with pitch and sulfur and into the scholar's study in order to fetch Cenodoxus's body, his students were also present. For these students, who represented the actual spectators themselves, the Jesuits' spiritual exercise thus became a theatrical and sensorial certainty" (KITTLER, 2010, p. 86, meu itálico). A original é assim: "Als im Finale zahllose Teufel mit Pech und Schwefel aus diesem Tor ins Studierzimmer des Gelehrten stürmten, um Cenodoxus' Leiche zu holen, wurde all seinen anwesenden Studenten, die nur uns faktische Zuschauer vertraten, ein jesuitisches Exerzieren zur theatralisch-sinnlichen Gewißheit” (KITTLER, 2011, p. 103, meu itálico).
} 
KITTLER, F. A verdade do mundo técnico. Tradução de Markus Hediger. Rio de Janeiro: Editora Contraponto, 2017.

KITTLER, F. Gramofone filme typewriter. Tradução de Daniel Martineschen e Guilherme Gontijo Flores. Belo Horizonte: Editoras da UFMG e UERJ, 2019.

LIBRANDI-ROCHA, M. Machado de Assis e o eco fonográfico. Revista de Estudos Literários, 6, pp. 263-285, 2016. Disponível em: https://impactumjournals.uc.pt/rel/article/view/2183-847X_6_12/3925 Acesso em 12. dez. 2020.

WINTHROP-YOUNG, G.; GANE, N. Friedrich Kittler: An Introduction. Theory, Culture \& Society, London, Vol. 23(7-8), pp. 5-16, 2006. Disponível em:

http://journals.sagepub.com/doi/pdf/10.1177/0263276406069874. Acesso em 09 jun. 2017.

Recebido em: 25 de junho de 2020 Aceito em: 11 de setembro de 2020 Publicado em dezembro 2020 